Arq. Bras. Med. Vet. Zootec., v.73, n.2, p.438-444, 2021

\title{
Evaluation of mean gray values of a cat with chronic renal failure: case report
}

[Avaliação dos valores médios de cinza em um gato com insuficiência renal crônica: relato de caso]

\author{
H.H. Arslan, U. Ozcan, Y. Durmus
}

Department of Internal Medicine, Faculty of Veterinary Medicine - University of Ondokuz May1s - Atakum, Turkey

\begin{abstract}
In this case, a 12-year-old female domestic cat with chronic renal failure (CRF), which had lived longer than the mean survival time for cats with that condition, was monitored to evaluate the effects of treatment and mean gray value (MGV) changes. The cat has lived for nearly four years since the diagnosis. Probiotics have been used as an additional, classical supportive therapy since the beginning of treatment. The temporal changes in renal MGV were statistically evaluated in the last year of the four-year period. The cat had a comfortable existence and good body condition all her life and probiotic therapy may have had a positive influence post-CRF diagnosis. Ultrasonography (US) examination is a commonly used tool for monitoring the CRF situation, but it is not particularly sensitive. Therefore, MGV may be more useful for the quantitative evaluation of the extent of renal failure. Also, to the best of our knowledge, this is the first report for a long-term clinical evaluation of MGV in a cat with CRF. The aim of this case report was the evaluation of the relationship between MGV and clinical and biochemical changes in a cat with chronic renal failure.
\end{abstract}

Keywords: chronic renal failure, mean gray value, probiotics, treatment, cat

\section{RESUMO}

No presente caso, uma gata doméstica de 12 anos com insuficiência renal crônica (IRC), que viveu mais do que o tempo médio de sobrevivência para gatos nessa condição, foi monitorada para avaliar os efeitos do tratamento e as alterações do valor cinza médio (MGV). A gata viveu quase quatro anos desde o diagnóstico. Os probióticos têm sido usados como uma terapia de suporte clássica adicional desde o início do tratamento. As alterações temporais do MGV renal foram avaliadas estatisticamente no último ano do período de quatro anos. A gata teve uma existência confortável e boas condições corporais durante toda a vida e a terapia com probióticos pode ter tido uma influência positiva após o diagnóstico de IRC. O exame de ultrassonografia (US) é uma ferramenta comumente usada para monitorar a situação da IRC, mas não é particularmente sensivel. Portanto, o MGV pode ser mais útil para a avaliação quantitativa da extensão da insuficiência renal. Além disso, até onde se sabe, este é o primeiro relatório de uma avaliação clínica de longo prazo de MGV em um gato com IRC. O objetivo deste relato de caso foi avaliar a relação entre o MGV e as alterações clínicas e bioquímicas em um gato com insuficiência renal crônica.

Palavras-chave: insuficiência renal crônica, valor médio de cinza, probióticos, tratamento, gato

\section{INTRODUCTION}

Chronic renal failure (CRF) is one of the most common health problems in cats, especially after 10 years of age (Sparkes et al., 2016). The CRF rate can reach $30 \%$ in older cats (Plantinga et al., 2005). There is no database showing the CRF rate for every country, but it is $1.9 \%$ in the general cat population in the USA and is diagnosed in $20 \%$ of cats presented at animal hospitals in Australia.
The main factors involved in the etiology of feline CRF are still unknown (Piyarungsri and Pusoonthornthum, 2017). CRF is a result of the gradual and irreversible loss of renal function caused by the loss of functional nephrons which are replaced by scar tissue (Collins, 2017).

Due to the loss of normal renal function, azotemia, uremia and other clinical signs appear, such as polyuria, polydipsia, dehydration, weight 
loss, pale mucous membranes and reduction in kidney size (Plantinga et al., 2005; Piyarungsri and Pusoonthornthum, 2017). The prognosis is poor because CRF irreversibly progresses to the death of the patient (Plantinga et al., 2005; Piyarungsri and Pusoonthornthum, 2017). The aim of this case report was the evaluation of the relationship between $\mathrm{MGV}$ and clinical and biochemical changes in an aged cat with chronic renal failure.

\section{MATERIALS AND METHODS}

A 12-year-old female domestic cat suffering from repeated vomiting was brought to the Ondokuz Mayis University Veterinary Faculty Small Animal Clinic. Anamnesis revealed frequent vomiting activity. A general physical examination was performed. Based on the patient's recent history, polyuria and polydipsia, and also mild dehydration and abdominal sensitivity, were detected. Hematological and biochemical analyses were done. Even though there was only one examination in the first year that showed neutropenia $\left(2.97 \times 10^{9} / \mathrm{L}\right)$, on a few occasions in the last year monocytopenia was demonstrated by hematological assessment. Increased serum creatinine and phosphorus levels were detected at the first record. Also, the serum urea level was in the normal range (creatinine $4.18 \mathrm{mg} / \mathrm{dL} \quad(<1.6$ $\mathrm{mg} / \mathrm{dL}$ ) (IRIS, 2019), phosphorus $10.61 \mathrm{mg} / \mathrm{dL}$ (3-6.1 mg/dL) (Fielder, 2015) urea $58.5 \mathrm{mg} / \mathrm{dL}$ (<76 mg/dL) (Paepe et al., 2015) at the first record. Nine months later, the urea and creatinine levels were second time markedly increased (creatinine $4.89 \mathrm{mg} / \mathrm{dL} \quad(<1.6 \mathrm{mg} / \mathrm{dL})$, urea $89.5 \mathrm{mg} / \mathrm{dL}(<76 \mathrm{mg} / \mathrm{dL})$. All other biochemical parameters were normal.

After the first examination, the cat was monitored and treated for approximately four years. Based on the cat's health status, every two or three months, biochemical, electrolyte and hematological analyses and US examinations were administered. During this period, there were no substantial changes in the cat's hematological parameters, but its serum creatinine level decreased to almost within the reference range at $2.29 \mathrm{mg} / \mathrm{dL}$ at one of the examinations. The changes in the serum urea and creatinine levels in the last year are shown in Figures 1 and 2.

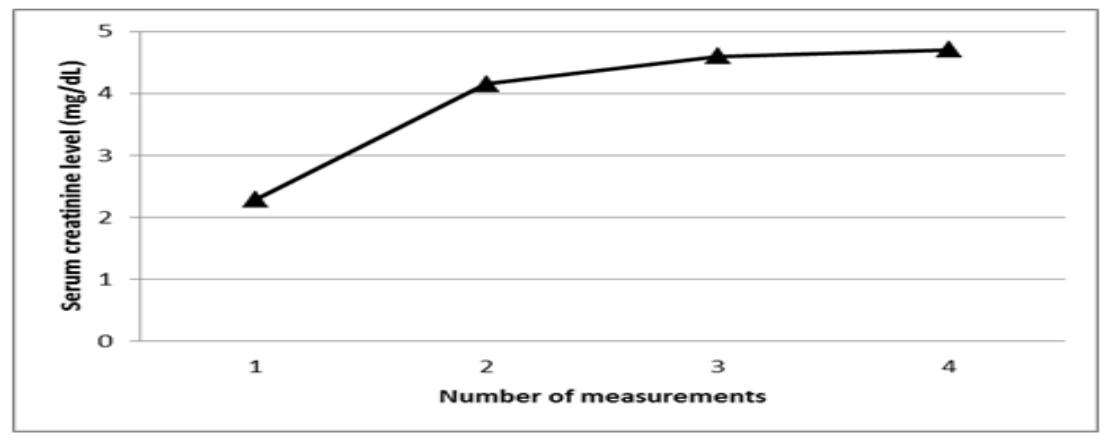

Figure 1. Changes in serum creatinine levels $(\mathrm{mg} / \mathrm{dL})$ of a 12-year-old female cat with CRF measured at three-month intervals in the last year.

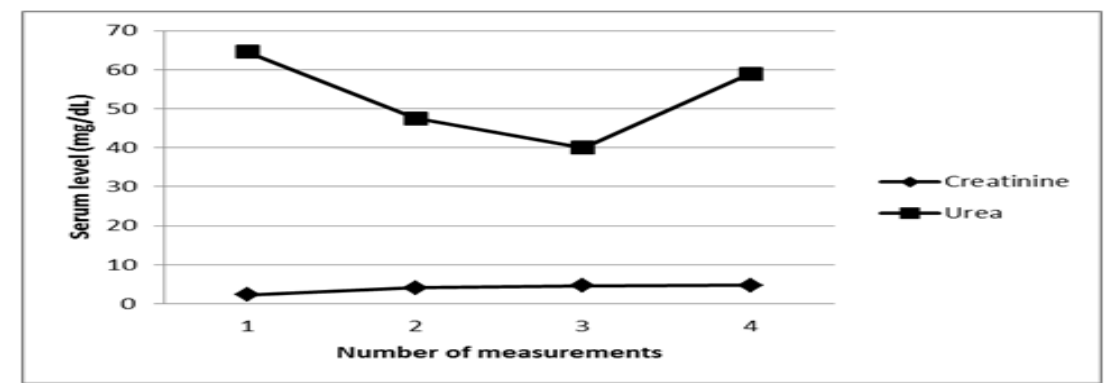

Figure 2. Serum urea and creatinine levels $(\mathrm{mg} / \mathrm{dL})$ of a 12-year-old female cat with CRF at three-month intervals in the last year. 
According to the International Renal Interest Society (IRIS) criteria, the cat was diagnosed with stage III renal failure at the first examination and treatment was commenced. In the first stage, an anti-emetic (metoclopramide), ranitidine, Ringer's lactate solution and a solution of amino acids and vitamins in combination (Duphalyte solution, Zoetis), were administered with intensive fluid therapy. In addition, electrolyte analyses were conducted; the serum potassium level had fallen below the normal range and potassium was added to the isotonic dextrose solution. Also, probiotics, fiber and a vitamin combination (NBL Gold Probiotics, Nobel) were used as supplementary treatments from the beginning of the treatment regime. The cat has been fed a prescription diet named Hill's k/d cat diet since the initial treatment.

However, when her biochemical parameters seriously deviated from the normal range, the cat needed intensive care in the OMU Small Animal Clinic. At other times, the cat, which has lived for nearly 1,400 days since the diagnosis of CRF, has received fluid treatment subcutaneously every two or three days at a private veterinary clinic. An Esaote MyLab Vet (Europe B.V., Netherlands) ultrasound device with a $5.0-8.0 \mathrm{MHz}$ micro convex probe was used for the ultrasonographic (US) examinations which were performed by the same operator during all visits to minimize artefact. The gain setting was set to $91 \%$, the focal point was at $5 \mathrm{~cm}$ to $7 \mathrm{~cm}$ depth, and the probe was fixed at $6.6 \mathrm{MHz}$.

\section{RESULTS}

In all US examinations, the shape and size of the kidneys were recorded. Images of the kidneys were taken longitudinally and transversely to assist in the determination of possible abnormalities such as fibrosis, cysts and kidney stones. In the first examination, the left and right kidneys were $2.16 \mathrm{~cm}$ and $2.69 \mathrm{~cm}$, respectively, on the longitudinal axis. Hyper-echogenic areas were observed in the right kidney, but no acoustic shadowing or twinkling artefact were detected. The kidneys were determined to be of normal shape in US examination. Three months after the first evaluation, the left and the right kidneys were
$2.44 \mathrm{~cm}$ and $3.34 \mathrm{~cm}$, respectively, longitudinally. Two more examinations were performed 3 months apart; in the first, the left and right kidneys were $2.25 \mathrm{~cm}$ and $2.32 \mathrm{~cm}$ long, respectively, and in the second, the left and right kidneys were $2.91 \mathrm{~cm}$ and $3.03 \mathrm{~cm}$ long, respectively.

The images from each US examination were saved so that temporal changes in MGV values could be assessed. For this purpose, longitudinal US images of both kidneys were taken. In the general examination, there was no abnormal echogenicity detected in the medullas of the kidneys. However, atrophy was demonstrated in both kidneys but there were no changes in the cortex/medulla ratio. Hyper-echogenicity was detected in some cortical areas and these changes were assumed to indicate fibrosis in the renal cortex. Subsequently, the development of changes in these areas was monitored with US examination for 12 months.

In the last year of the cat's treatment, the US images were also evaluated to determine the MGV. The extent of changes in echogenicity over time was evaluated and the MGV was calculated with ImageJ, version 1.480, with the region of interest (RoI) evaluated in six square, $16 \times 16$ pixels RoI (National Institutes of Health, Bethesda, USA). The results of four different US examinations over the course of the most recent year of treatment were used, with a grayscale range from 0 to 256 used. In this way, MGV could be calculated.

The normality of the $16 \times 16$ pixel RoI data was evaluated with the Shapiro-Wilk Test and they were determined to be normally distributed. Differences in grayscale values were evaluated with the ANOVA (one-way analysis of variance) test. All data are presented as mean + standard error of the mean (S.E.M). Differences were considered significant when $\mathrm{P}$ values were less than 0.05. For the left kidney, the MGV values differed significantly $(\mathrm{P}<0.05)$ for all 4 tests over the most recent 12-month period, and for the right kidney, the MGV values did not differ significantly $(\mathrm{P}>0.05)$ over the most recent 12 month period (Figure 3-4). 


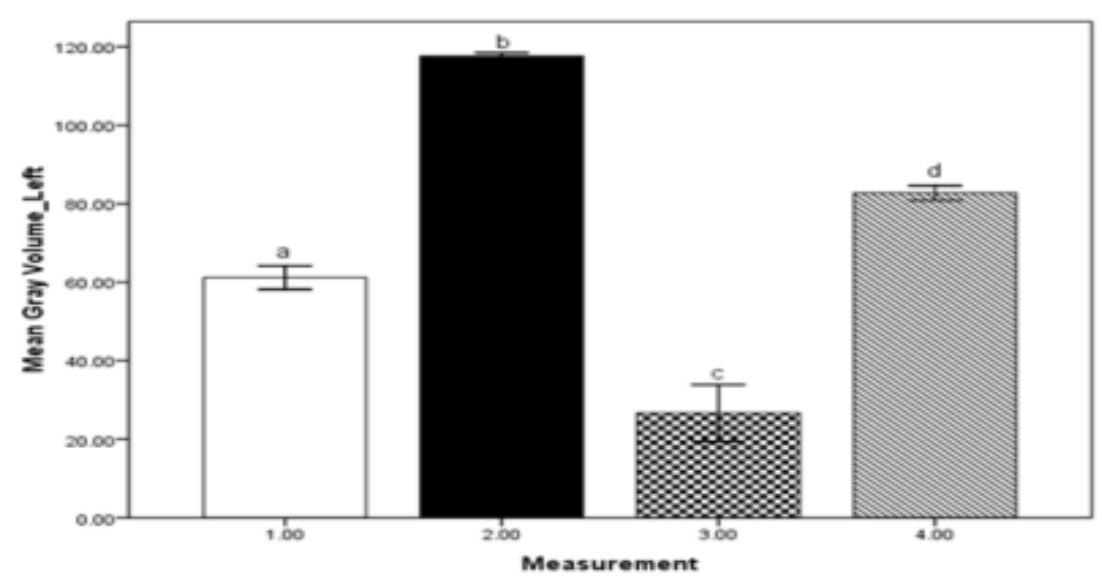

Figure 3. MGVs of four US of the left kidney examinations of a 12-year-old female cat with CRF that were recorded at three-month intervals in the last year of treatment.

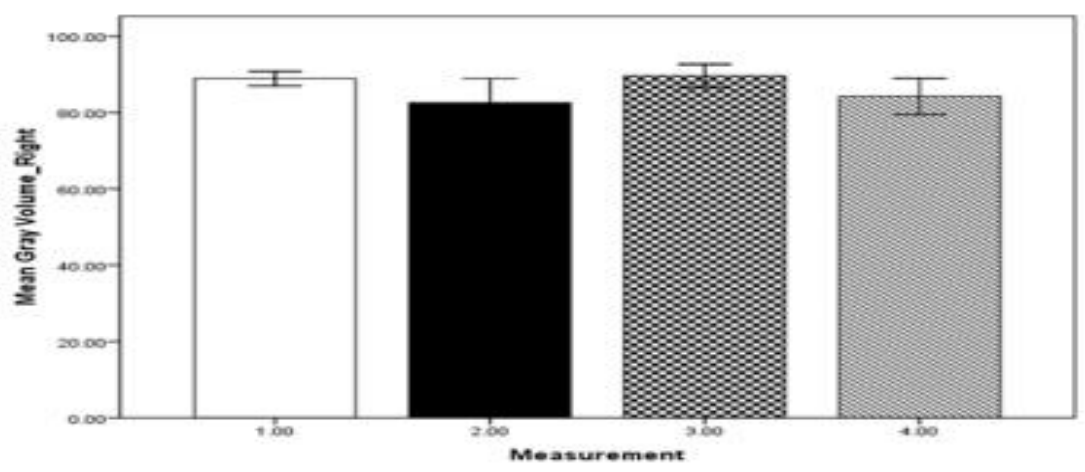

Figure 4. MGVs of four US of the right kidney examinations of a 12-year-old female cat with CRF that were recorded at three-month intervals in the last year of treatment.

\section{DISCUSSION}

A 12-year-old female domestic cat suffering from repeated vomiting was brought to the Ondokuz Mayis University Veterinary Faculty Small Animal Clinic. Anamnesis revealed frequent vomiting activity. The impairment of kidney function increases with age in cats; therefore, CRF is a common clinical condition. The cat presented in this case was 12 years old at the time of the clinical diagnosis of CRF. CRF may affect 30$40 \%$ of cats, especially those older than 10 years (Plantinga et al., 2005; Boyd et al., 2008; Sparkes et al., 2016). In the United Kingdom, renal disease was the most common cause of mortality in cats more than 5 years of age.

At 15 years and over, the proportion of deaths from CRF could be $>13 \%$ (Sparkes et al., 2016). Due to progressive and irreversible loss of kidney function, clinical signs, such as azotemia and uremia, increasingly appear. These cats have a poor prognosis because renal dysfunction generally progresses to the last stage in cats with CRF (Plantinga et al., 2005). If the serum creatinine level is between $2.9 \mathrm{mg} / \mathrm{dL}$ and $5.0 \mathrm{mg} / \mathrm{dL}$ in cats, it is indicative of stage III of CRF (IRIS, 2019). In the current case, the serum creatinine level was $4.18 \mathrm{mg} / \mathrm{dL}$ at the first examination.

Since the diagnosis of CRF, the cat has lived for 3.8 years. Survival times have been reported in different studies. Regardless of the stage of the disease, the mean survival time is 2.1 years (771 days) from diagnosis. If the diagnosis is made in the early stage of the disease, i. e., at stage II, a cat can live for 8.5 years, with the average time being 3.15 years ( 1,151 days). The mean survival time of cats with CRF detected in stage III is 1.86 years (679 days), with possible life duration of 5.75 years. However, for diagnosis in stage IV, the 
average survival time is only 1.16 months (35 days) (Boyd et al., 2008).

In CRF patients, probiotics of different types and at different dosages can reduce the levels of some uremic toxins (Alatriste et al., 2014). In CRF, toxins are produced by bacterial communities of the large bowel termed the gut microbiota, which are altered and become dysbiotic. Rossi et al. (2016) reported that symbiotic bacterial therapy can reduce the levels of some uremic toxins in patients with CRF. Also, after antibiotic treatment, dysbiosis can be treated by probiotics. In addition, Lippi et al. (2017) reported that after two months of administration of VSL\#3, which is a lyophilized bacterial product containing four strains of Lactobacillus (L. acidophilus, L. casei, $L$. delbrueckii subsp. bulgaricus and $L$. plantarum) and 3 strains of Bifidobacterium (B. breve, $B$. infantis and $B$. longum), the treated dogs showed a significant improvement in glomerular filtration rate, urinary concentration ability and a significant reduction in the level of creatinine $(\mathrm{P}<0.05)$ in comparison with the control dogs.

Lippi et al. (2017) further reported that these findings support the potential role of probiotics in reducing the progression of $\mathrm{CRF}$. High dose, a multi-strain probiotic product that contains viable, lyophilized bacteria (Bifidobacterium bifidum, Bifidobacterium longum, Enterococcus faecium, Lactobacillus acidophilus and Lactobacillus rhamnosus) (NBL Gold Probiotics, Nobel), has been administered orally to this cat two times daily since the beginning of its treatment. The lactobacilli found in cats are typical intestinal lactobacilli, e. g., Lactobacillus acidophilus, L. johnsonii, L. reuteri, L. sakei and L. salivarius, which can be seen in other animals, including humans. Bifido bacteria constitute a major proportion of gut bacteria in healthy cats. In addition, there are several unique Bifidobacterium species in cats (Grześkowiak et al., 2015).

Ultrasound is a very useful, non-invasive technique for the evaluation of abdominal disorders. However, associated with diffused parenchymal renal diseases, structural modifications can occur, and it is difficult to assess these changes with US. Renal cortical echogenicity is usually evaluated in comparison with liver and spleen echogenicity, but it is not objective. However, increased cortical echogenicity, or cortical and medullary echogenicity is one of the most commonly reported signs of chronic or acute renal disease in veterinary medicine (Zotti et al., 2015). Despite severe renal failure, kidneys may show normal echogenicity in US examination (Banzato et al., 2017). However, Lamb et al. (2018) compared US findings for cats with azotemia and without azotemia and reported that perinephric fluid, smaller kidneys, hyperechoic renal cortex, loss of corticomedullary differentiation, renal calculi, enlarged kidneys and dilated renal pelvis were notably associated with azotemia. In the current case, small kidney size and echogenic changes were detected.

Images can be affected by the techniques used to generate them and by the interpretations of the operator. New evaluation parameters, including MGV, which shows the smallest volume unit (mean intensity of grayscale voxels) in a particular region, allow more objective assessment; the appropriate software can be used for the quantitative assessment of ultrasound data (Zotti et al., 2015; Guerriero et al., 2013). In parallel with the inflammatory and degenerative changes associated with feline renal failure, renal echogenicity increases. Therefore, MGV can be a worthwhile technique for the identification of severe renal damage in cats (Banzato et al., 2017). The MGV results for felines' kidneys have a more linear correlation with histological scores for degeneration and inflammation than canine samples (Zotti et al., 2015).

Moreover, MGV, which has a sensitivity of $80.6 \%$ and a specificity of $56 \%$, can be a useful tool for distinguishing between normal and pathological feline kidneys (Zotti et al., 2015). Banzato et al. (2017) investigated the relationship between the echogenicity of the renal cortex assessed with MGV and histopathological findings for the diagnosis of kidney diseases in dogs and cats. They concluded that renal cortical echogenicity is valuable for the identification of serious renal damage in cats. However, it is not sensitive enough for the diagnosis of the moderate damage associated with renal diseases (Zotti et al., 2015; Banzato et al., 2017).

In the present case, the first ultrasonographic examination showed no focal pathological changes or kidney stones in the renal medulla but hyperechogenic areas were observed in the right kidney and the size of both kidneys had decreased. 
Although there were no evident changes in US findings over the studied 12-month period, significant statistical differences $(\mathrm{P}<0.05)$ were detected for the MGV for the left kidney which may be explained by a treatment response because during a part of the treatment period, serum creatinine and urea levels were markedly lower than previously recorded. However, that does not signify that renal regeneration is occurring or can occur.

Since the beginning of the MGV assessments, the right kidney has shown some hyperechogenic areas in the cortex which may explain the high MGV values for the full duration of the monitoring period. However, the left kidney did not have notable hyperechogenic areas. In contrast, the right kidney's MGV values were continually high in the evaluation period, a finding which was compatible with the echogenic findings in US.

\section{CONCLUSIONS}

The cat referred to in this case has lived much longer than the average survival time for cats diagnosed at the same stage of renal failure. Throughout the duration of treatment, she has had good body condition. The supplementary use of probiotics may be a good supportive treatment to prolong the survival of cats with CRF but more comprehensive studies are needed on this subject. Ultrasonography is a useful, non-invasive method for the determination of the extent of abdominal diseases and other disorders in animals, but the findings can differ according to the practitioner's experience and the device and probe settings. In diseases like CRF where there are diffuse changes in the visceral organs, it is challenging to detect and quantify abnormalities via US. To make an objective assessment of US findings in CRF patients, MGV measurement appears to be useful and could therefore be a useful complementary technique for monitoring CRF situations. Although there are two research reports about MGV assessment in cats with renal disease, authors could not find any reports of the monitoring of MGV in cats with CRF. Therefore, to the best of our knowledge, this is the first report for a long-term clinical evaluation of MGV in a cat with CRF. Obviously, the findings of a single case report do not provide sufficient data; however, its findings do suggest the potential value of more studies that evaluate the relationship between $\mathrm{MGV}$ changes and the progression of CRF stages which cannot be determined clinically and biochemically.

\section{ACKNOWLEDGEMENT}

The authors thank Dr Gregory T. Sullivan for proofreading an earlier version of this manuscript.

\section{REFERENCES}

ALATRISTE, P.V.M.; ARRONTE, R.U.; ESPINOSA, C.O.; CUEVAS, E. Effect of probiotics on human blood urea levels in patients with chronic renal failure. Nutr. Hosp., v.29, p.582-590, 2014.

BANZATO, T.; BONSEMBIANTE, F.; ARESU, L.; ZOTTI, A. Relationship of diagnostic accuracy of renal cortical echogenicity with renal histopathology in dogs and cats, a quantitative study. BMC Vet. Res., v.13, p.24, 2017.

BOYD, L.M.; LANGSTON, C.; THOMPSON, K. et al. Survival in cats with naturally occurring chronic kidney disease (2000-2002). J. Vet. Intern. Med., v.22, p.1111-1117, 2008.

COLLINS, S. Nutritional support of cats and dogs with renal disease. Vet. Nurs. J., v.32, p.254-256, 2017.

FIELDER, S.E. Serum biochemical reference ranges. The merck veterinary manual: USA: OCEANO. 2015. Available in: https://www.msdvetmanual.com/specialsubjects/reference-guides/serum-biochemicalreference-ranges. 2020

GRZEŚKOWIAK, Ł.; ENDO, A.; BEASLEY, S.; SALMINEN, S. Microbiota and probiotics in canine and feline welfare. Anaerobe, v.34, p.1423, 2015.

GUERRIERO, S.; PILLONI, M.; ALCAZAR, J.L. et. al. Tissue characterization using mean gray value analysis in deep infiltrating endometriosis. Ultrasound Obstet. Gynecol., v.41, p.459-464, 2013.

IRIS staging of CKD (modified 2019). Available in: http://www.iris-kidney.com/pdf/IRIS_ Staging_of_CKD_modified_2019.pdf. 2020

LAMB, C.R.; DIRRIG, H.; CORTELLINI, S. Comparison of ultrasonographic findings in cats with and without azotaemia. J. Feline Med. Surg., v.20, p.948-954, 2018. 
LIPPI, I.; PERONDI, F.; CECCHERINI, G.; MARCHETTI, V.; GUIDI, G. Effects of probiotic VSL\#3 on glomerular filtration rate in dogs affected by chronic kidney disease: a pilot study. Can. Vet. J., v.58, p.1301-1305, 2017.

PAEPE, D.; GHYS, L.F.; SMETS, P. et al. Routine kidney variables, glomerular filtration rate and urinary cystatin $\mathrm{C}$ in cats with diabetes mellitus, cats with chronic kidney disease and healthy cats. J. Feline Med. Surg., v.17, p.880$888,2015$.

PIYARUNGSRI, K.; PUSOONTHORNTHUM, R. Risk and protective factors for cats with naturally occurring chronic kidney disease. $J$. Feline Med. Surg., v.19, p.358-363, 2017.

PLANTINGA, E.A.; EVERTS, H.; KASTELEIN, A.M.; BEYNEN, A.C. Retrospective study of the survival of cats with acquired chronic renal insufficiency offered different commercial diets. Vet Rec., v.157, p.185$187,2005$.
ROSSI, M.; JOHNSON, D.W.; MORRISON, M. et al. Synbiotics easing renal failure by improving gut microbiology (SYNERGY): a randomized trial. Clin. J. Am. Soc. Nephrol., v.11, p.223-231, 2016.

SPARKES, A.H.S.; CANEY, S.; CHALHOUB, $\mathrm{S}$. et al. ISFM consensus guidelines on the diagnosis and management of feline chronic kidney disease. J. Feline Med. Surg., v.18, p.219239, 2016.

ZOTTI, A.; BANZATO, T.; GELAIN, M. E. et. al. Correlation of renal histopathology with renal echogenicity in dogs and cats: an ex-vivo quantitative study. BMC Vet. Res., v.11, p.99, 2015. 